\title{
On the diversity and distribution of the genus Frullania in Northern Holarctic
}

\author{
Yuriy S. Mamontov ${ }^{1,3 *}$, John J. Atwood ${ }^{2}$, and Anna A. Vilnet ${ }^{3}$ \\ ${ }^{1}$ Tsitsin Main Botanical Garden, Russian Academy of Sciences, 127276, Moscow, Russia \\ ${ }^{2}$ Missouri Botanical Garden, 63166-0299 St. Louis, Missouri, U.S.A. \\ ${ }^{3}$ Polar-Alpine Botanical Garden-Institute, Russian Academy of Sciences, 184256, Kirovsk, Russia
}

\begin{abstract}
In Northern Holarctic, the liverwort genus Frullania includes 61 accepted species and at least ten undescribed new species making the genus the most diversified in that region. The presence of numerous endemics points to the role of the arising of new species, while the possible exchange between the continents through the Atlantic and Beringia land bridges resulted in species common for both North America and Eurasia.
\end{abstract}

\section{Introduction}

Frullania currently represents the sole extant genus of the family Frullaniaceae (Porellales, Jungermanniopsida) and the largest genus of liverworts (Marchantyophyta). The genus is nearly cosmopolitan and includes more than 2000 published binomials [1, 2], with the number of accepted names being significantly lower than that number but still fluctuating because of ongoing revisionary work [3-5]. The Northern Nearctic (Canada and the U.S.A.) and Northern Palearctic (Europe, Siberia, the Russian Far East) - the parts of Northern Holarctic - have specific Frullania floras, which include both endemics and widely distributed species. In the 20th century, the treatments of Frullania in these regions utilized mainly the wide concept of some species (such as F. eboracensis, F. inflata, F. oakesiana, $F$. tamarisci), so that these species were known to have almost transcontinental distribution in both North America and Eurasia. However, molecular phylogenetic studies published from the 2000s have provided narrow concepts of numerous taxa and increased the number of accepted species as well as the number of endemic ones [5-9]. The subgeneric and sectional assignments have also been changed for some species, that changes the treatment of contribution of different Frullania subgenera to the liverwort flora of Northern Holarctic.

\section{Contribution of different subgenera of the genus Frullania to the liverwort flora of Northern Holarctic}

The genus is divided into 12 subgenera [10-13], of which the subgenera Caulisequa, Chonanthelia, Diastaloba, Frullania, Frullaniopsis, Meteoriopsis, and Trachycolea are

\footnotetext{
* Corresponding author: yur-mamontov@yandex.ru
} 
represented in the liverwort flora of Northern Holarctic. The contribution of different Frullania subgenera is of varying significance in different regions.

\subsection{Subgenus Caulisequa}

The representatives of this subgenus are currently distributed mainly in Neotropics of Americas, also in Australasia and Africa [12], while in the Northern Nearctic the subgenus includes only $F$. obcordata $[10,12]$. According to the data in $[10,12]$ this species represented a paraphyletic taxon, which needs further revision to establish an amount of its member species and their distribution.

\subsection{Subgenus Chonanthelia}

The genus is mostly Neotropical, but has isolated representatives, including endemics, in all other floral kingdoms [1]. The subgenus contains four sections (Chonanthelia, Cladocarpica, Inflatae and Pluricarinatae) [9, 11], all of which are known in North America. The monospecific section Chonanthelia includes the type species of the subgenus, F. gibbosa, which is distributed in the U.S.A. also in Mexico, West Indies, Central and South America. The section Cladocarpica includes here one species F. riojaneirensis, which is known in the U.S.A., Mexico, West Indies, Central and South America, Africa, and Asia. The recently described section Inflatae includes here three species, namely $F$. inflata, $F$. rappii, and $F$. sabaliana - endemics of North America. There are also two new undescribed species of this section, first of which is still known only in Texas, while the second in Arizona and Baja California [14]. Section Pluricarinatae includes here three species $-F$. cobrensis, $F$. cuencensis, and $F$. mexicana. Outside the U.S.A, $F$. cobrensis and $F$. cuencensis are known in West Indies $[3,15]$, while $F$. cuencensis and $F$. mexicana are distributed in Central and South America $[1,15]$.

\subsection{Subgenus Diastaloba}

The subgenus is paraphyletic and was found to contain four lineages [10], of which subgenus Caulisequa was typified and formally described only recently [12]. Three other lineages remain in need of typification and circumscription and contain numerous representatives distributed in Africa, Asia, Australasia, and South America. In the Northern Nearctic, the subgenus is represented by the species $F$. taxodiocola, which is known in the U.S.A. $[3,15]$.

\subsection{Subgenus Frullania}

The representatives of this subgenus are currently distributed mainly in Holarctic, although isolated species are known in Neotropics of South America [16, 17] and Paleotropic of Asia [18). The genus includes two sections, namely Frullania and Microphyllae. In North America and Northern Eurasia, the section Frullania contains 14 species [7-9, 19], of which only two ( $F$. subarctica and $F$. tamarisci) are distributed in both continents. Frullania subarctica has been found in Arctic, Kola Peninsula, Siberia, and the Russian Far East [7, 8], while $F$. tamarisci is widely distributed in Europe and is known in Northeastern America. Other species of the subgenus are endemics. Frullania asagrayana and $F$. selwyniana are known in Eastern North America, while $F$. californica, $F$. chilcootiensis, $F$. franciscana, and $F$. nisquallensis are distributed in Western North America. Frullania acicularis, $F$. calcarifera, $F$. polysticta, F. sergiae, and $F$. teneriffae are known in Europe 
and Macaronesia, while $F$. appendiculata is distributed in the south of the Russian Far East. The representatives of section Microphyllae, namely $F$. fragilifolia and F. microphylla, are endemics of Europe.

\subsection{Subgenus Frullaniopsis}

This recently described subgenus includes several species distributed in Holarctic (excluding Arctic subregion), while in other floral kingdoms there were found no Frullaniopsis species [9]. In Northern Nearctic and Northern Palearctic, the subgenus contains 15 species, that is 11 known species and at least four new undescribed species [20]. Frullania austinii, F. cleistostoma, F. oakesiana, and F. stylifera are distributed in both North America and Northern Eurasia, while other species are endemics. Frullania bolanderi and F. catalinae are distributed only in Western North America, F. neomexicana, $F$. wrightii, and one undescribed species (named as F. saxicola 2-3 in [9]) are known in the Mountain States of the U.S.A. Another undescribed species (named F. saxicola 1 in [9]) is distributed in Eastern North America. The European $F$. illirica has not been sequenced, so the specific level of this taxon remains in need of confirmation. In Siberia and the Russian Far East there are $F$. pseudoinflata, F. takayuensis, and two new undescribed species distributed in Primorye Territory and Sakhalin Region [20].

\subsection{Subgenus Meteoriopsis}

This mostly tropical subgenus contains three sections $[10,11]$ and numerous representatives, only three of which ( $F$. cucullata, $F$. donnellii, and $F$. kunzei) are distributed in North America. Besides Nearctic, all three species are known in the Neotropics of North America and (in the case of F. kunzei) Central and South America.

\subsection{Subgenus Trachycolea}

The most diversified and taxonomically complex subgenus, which is represented in the Northern Nearctic and Northern Palearctic by six sections. The section Acutilobae is considered here in a broad sense until the taxonomy of this group and its closest relatives is established. In the present sense this section corresponds to the supported clade in [10], which is composed by sections Acutilobae, Irregulares, Integristipulae I, Orientales, Ornitocefalae I, and includes the paraphyletic taxon $F$. ericoides (subsection Ericoides) and its relatives. This section is represented here by $F$. ericoides, which is distributed in Eastern and Southwestern North America and Macaronesia. Recently, it was shown that $F$. ericoides is a paraphyletic taxon [10], which needs further revision to establish an amount of its member species and their distribution. Most representatives of another section, Australes, are distributed in East and Southeast Asia, Australasia, Africa, and South America, while only one of them, F. parvistipula, has been found in the Northern Holarctic, that is in Baikal Siberia (Russia) and Arizona (the U.S.A.) [20]. The monospecific section Diversitextae includes $F$. diversitexta, which is distributed in Japan, the Russian Far East, Republic of Korea, and China [13]. This species reveals close molecular and morphological affinity to another monospecific section of subgenus Trachycolea, namely Planae. The latter section includes $F$. plana, an endemic of Eastern North America. The section Integristipulae II is considered here to contain all taxa of the supported clade in [10], which is composed by species $F$. davurica and $F$. jackii (Integristipulae II) and its closest relatives. This section is now in process of being circumscribed [20]. The sequenced representatives of this section are distributed mainly in East Asia [10, 20]. In Northern Nearctic and Northern Palearctic, the section includes ten known species and at least three 
new undescribed ones. Two species, $F$. davurica and $F$. riparia, are distributed in both continents, while other species of the section are endemics. Frullania riparia is known in Europe, the Mountain States of the U.S.A. and in Eastern North America, while F. davurica is distributed in Southern and Eastern Siberia, the Russia Far East, and Alaska, perhaps also in Japan, Korean Peninsula, and the North of China. The records of $F$. davurica from China at least partly belong to another related species $F$. rotundistipula [20], which can also be found in Japan. Frullania brittoniae is endemic to Eastern North America, F. jackii is distributed in Europe, while $F$. aeolotis var. aberrans, F. ignatovii, F. muscicola, F. sinensis, $F$. taradakensis, $F$. usamiensis, and three new undescribed species have been found in Eastern Siberia, the Russian Far East, China, Japan, and the Republic of Korea [20, 21]. Section Trachycolea includes eight proven species [6, 10, 20], of which only one (F. caucasica) is known in both Nearctic (New Mexico) and Palearctic (Europe, Ural Mts., Western and Eastern Siberia). The other seven species of the section are endemics. In Eastern North America, F. appalachiana, F. eboracensis, and F. virginica are distributed, while in Eurasia there are F. azorica (Macaronesia), F. dilatata (Europe, Asia Minor and Southern Siberia), also F. conistipula and F. koponenii (Eastern Siberia, the Russia Far East, and Japan) [20].

\section{Conclusion}

In the Northern Holarctic, that is in its Nearctic (Canada and the U.S.A.) and Palearctic (Europe, Siberia, and the Russian Far East) parts, the Frullania flora includes 61 accepted species (plus ten new ones projected to be described) belonging to seven subgenera and 16 sections. It makes the genus the most diversified in that region. There are 11 species of three subgenera and six sections, which are common for both North America and Northern Eurasia. The presence of these species points to the role of an exchange of species between the continents, possibly through the Atlantic (cases of $F$. austinii, F. oakesiana, F. riparia, $F$. stylifera, $F$. tamarisci) and Beringia (cases of $F$. caucasica, F. cleistostoma, $F$. davurica, F. subarctica) land bridges. Generally, in the Northern Nearctic there are 39 accepted (plus five undescribed) species of seven subgenera and 15 sections, while in the Northern Palearctic there are 33 accepted (plus five undescribed) species of three subgenera and eight sections. Four subgenera (Caulisequa, Chonanthelia, Diastaloba and Meteoriopsis) occur in the Northern Nearctic, but are not represented in the Northern Palearctic (although they all are known in Southeast Asia, and some of them in East Asia outside Russia). These mostly tropical subgenera occur in the Nearctic due to the direct contact between the latter region and Neotropics in the U.S.A. and Mexico. They include a third of the Frullania flora of the U.S.A., that is 13 accepted species, of which two are endemics of the Nearctic. On the other hand, section Integristipulae II of subgenus Trachycolea includes in the Nearctic only three species, of which only one ( $F$. brittoniae) is endemic, whereas in the Northern Palearctic this section includes nine accepted species (plus three undescribed) due to the direct contact between the Northern Palearctic and East Asia. Of these species, $F$. ignatovii and $F$. jackii are endemics of Eastern Siberia and Europe, respectively, while the six other species are distributed also in East Asia besides Russia. The diversity of other, mostly Holarctic groups of the genus, that is section Trachycolea and subgenera Frullania and Frullaniopsis, is similar in both the Northern Nearctic and the Northern Palearctic. Indeed, section Trachycolea includes in the Northern Nearctic three endemic species, while in the Northern Palearctic there are four such species. Analogously, subgenus Frullania includes six and eight endemic species, respectively, and subgenus Frullaniopsis contains four and three such species, respectively. Therefore, the arising of new endemic species also has made a certain contribution to the diversity of the genus in both the Northern Nearctic and the Northern Palearctic. Moreover, the phylogenetic relationships within these groups, as 
well as the similar number and similar patterns of the distribution of its endemic members may indicate more or less a synchronous diversification event, that may have been caused by the climatic changes started in Oligocene.

The reported study was partially funded by RFBR, project number 19-04-01270. We thank Ministry of Higher Education and Science of Russia for grant 075-15-2021-678 supporting Center of Common Use «Herbarium MBG RAS».

\section{References}

1. Y. Yuzawa, J. Hattori Bot. Lab. 70 (1991)

2. M. von Konrat, J. Hentschel, J. Heinrichs, J. E. Braggins, T. Pócs, Nova Hedwigia 91 (2010)

3. R. M. Schuster, The Hepaticae and Anthocerotae of North America, east of the hundredth meridian, Vol. 5 (Field Museum of Natural History, Chicago, 1992)

4. S. R. Gradstein, S. P. Churchill, N. Salazar-Allen, Guide to the bryophytes of tropical America (The New York Botanical Garden Press, New York, 2001)

5. B. E. Carter, J. Larraín, A. Manukjanová, B. Shaw, A. J. Shaw, J. Heinrichs, P. de Lange, M. Suleiman, L. Thouvenot, M. von Konrat, Mol. Phyl. Evol. 107 (2017)

6. A. Bombosch, A. Wieneke, A. Busch, R. Jonas, H.-P. Kreier, B. Shaw, A. J. Shaw, J. Heinrichs, Plant Syst. Evol. 290 (2010)

7. J. Heinrichs, J. Hentschel, A. Bombosch, A. Fiebig, J. Reise, M. Edelmann, H.-P. Kreier, A. Schäfer-Verwimp, S. Caspari, A.R. Schmidt, R.-L. Zhu, M. von Konrat, B. Shaw, A.J. Shaw, Mol. Phyl. Evol. 56 (2010)

8. A. A. Vilnet, E.A. Borovichev \& V. A. Bakalin, Phytotaxa 173, 1 (2014)

9. Y. S. Mamontov, A. A. Vilnet, J. J. Atwood, N. A. Konstantinova, Nova Hedwigia Beiheft 150 (2020)

10. J. Hentschel, M. von Konrat, T. Pócs, A. Schäfer-Verwimp, A.J. Shaw, H. Schneider, J. Heinrichs, Mol. Phyl. Evol. 52 (2009)

11. J. Hentschel, M. von Konrat, L. Söderström, A. Hagborg, J. Larraín, P. Sukkharak, J. Uribe, L. Zhang, Phytotaxa 220 (2015)

12. G. Winter, A. Schäfer-Verwimp, Frahmia 19 (2020)

13. J. J. Atwood, A. A. Vilnet, Yu. S. Mamontov, Crypt., Bryol. 42, 3 (2021)

14. J. J. Atwood, A. A. Vilnet, Yu. S. Mamontov, Novon (to be published)

15. J. J. Atwood, Bryophyte Flora of North America (Missouri Botanical Garden, Saint Louis, Missouri, 2017) (provisional publication for the Flora of North America)

16. Y. Yuzawa, S. Hattori, J. Jap. Bot. 64 (1989)

17. E. Lima, A. L. Ilkiu-Borges, S. R. Gradstein, Phytotaxa 456, 1 (2020)

18. S. Hattori, J. Hattori Bot. Lab. 35 (1972)

19. J. J. Atwood, Yu. S. Mamontov, Botanica Pacifica. 9, 2 (2020)

20. Y. S. Mamontov, A. A. Vilnet, J. J. Atwood, N. A. Konstantinova, Nova Hedwigia (to be published)

21. E. V. Sofronova, Yu. S. Mamontov, A. D. Potemkin, Nov. Syst. Plant. Non Vascul. 47 (2013) 